\title{
The Social Psychology of Identity and Inter-group Conflict: From Theory to Practice
}

\author{
ESRa CuHAdar \\ Bilkent University \\ AND \\ Bruce DAyton \\ Syracuse University
}

\begin{abstract}
This paper reviews the seminal theories of social psychology which have guided scholarship on inter-group conflicts and describes how these theories have been used by conflict resolution practitioners to design Track Two diplomacy initiatives among citizens in conflict zones. The authors hope that such a review will provide scholars of conflict resolution and international politics with a better understanding of how complex social theories are adapted for use in the applied world, and how gaps between theory and practice can be identified and addressed. The paper begins with an overview of three of the main theoretical contributions of social psychology to the problem of inter-group conflict: social identity theory, stereotyping and prejudice, and contact theory. We then review how these theories have been applied by conflict resolution specialists in international and ethnic conflicts as they have sought to moderate intergroup hostilities in conflict zones. The paper concludes with an analysis of the gaps between theory and practice, namely: theory of change gap, transfer strategies gap, and unit of analysis gap. Finally, based on the reviewed social psychology research, the article makes policy recommendations about how these gaps between theory and practice can be narrowed.
\end{abstract}

Keywords: inter-group conflict, social identity theory, contact hypothesis theory, Track Two diplomacy, conflict resolution interventions, theories of change

Track Two diplomacy is an unofficial peacebuilding process in which representatives from communities in conflict are brought together by a third party to consider the underlying roots of the conflict and means for its positive transformation (Davies and Kaufman 2002). ${ }^{1}$ During these encounters the third party carefully facilitates contact between each group in order to increase empathy and understanding, build trust, and/or identify options for conflict settlement that can be undertaken at the official "track one" level. Over the past

\footnotetext{
${ }^{1}$ Other terms used in the literature to describe such processes include: interactive conflict resolution (Fisher 1997); interactive problem-solving workshops (Kelman 1995); sustained dialogue (Saunders 1999); unofficial diplomacy (Volkan 1991); and citizens diplomacy (Davies and Kaufman 2002). We use the term Track Two diplomacy as a generic term to refer to all types of unofficial and interactive conflict resolution efforts.
} 
several decades this field of conflict management has emerged as an important supplement to traditional diplomatic initiatives, particularly in conflict zones where intractable identity-based conflicts have proven resistant to official peacemaking efforts (Fisher 2005).

Most of the original founders of Track Two diplomacy were university-based "scholar-practitioners" who in the 1960s sought to better manage violent intergroup conflicts by applying new theories of inter-group relations to their transformation. Since that time the practice of Track Two diplomacy has spread far beyond the academy and numerous non-governmental organizations, thinktanks, and private individuals have applied it to an ever-widening collection of conflicts. This second generation of practitioners ${ }^{2}$ is more applied than theoretical and, as a result, a gap between evolving social-psychological research on inter-group conflict and the practice of Track Two diplomacy has emerged. This paper will examine this gap by connecting theory to practice. We begin by reviewing three seminal theories of social psychology which have guided scholarship on inter-group conflicts: social identity theory, stereotyping and prejudice, and contact theory. We consider how these theories were originally laid out and how they have been challenged and modified over the years. We then describe how social psychological theories about inter-group conflict have been applied to international and ethnic conflicts by conflict resolution professionals. Finally, we analyze the gaps that have emerged between theory and practice and make recommendations about how these gaps can be narrowed.

\section{Intractable Conflict and Social Identity Theory}

Social psychologists have struggled over the years to explain why some groups engage in collective conflict behavior while other groups do not, how levels of heterogeneity and homogeneity within societies do or do not contribute to intergroup conflict, and what factors explain the ability of some groups to maintain cohesion as they engage in conflict while other groups lose cohesion. But few theories have been more important to the evolution of applied work in intractable conflicts than social identity theory (Tajfel 1974; Tajfel and Turner 1979, 1986).

Social identity theory, described by Brown (2000) as one of social psychology's "pre-eminent" theories, proceeds from the premise that human beings are, by nature, a pattern recognition species and that the human ability to distinguish between objects, circumstances, and behavior is a functional cognitive process necessary for survival. Within the social realm, this human tendency to search for patterns naturally results in the creation of in-groups and out-groups; categorizations of people who are "like us" and people who are "unlike us." In-group/ out-group categorization allows individuals to recognize other humans by type and also to draw on mental constructs that set expectations and guide behavior as they navigate their social interactions.

The clustering of people into in-groups and out-groups is not alone enough to trigger inter-group conflict, rather, it is the desire to maintain a high-level of personal and group esteem that leads to the kinds of biases and stereotypes that are familiar to researchers of inter-group conflict (Rubin and Hewstone 2004). Here the argument is that individuals have a basic need to view the groups they belong to in a positive light in order that they can view themselves in a positive light as well (Brewer and Brown 1998). This need for self and group esteem provides a motivation for individuals to evaluate their own group more favorably than they do other groups (Hewstone, Rubin, and Willis 2002). By degrading

\footnotetext{
${ }^{2}$ Throughout the paper, practitioners, refers to those who organized, planned, and/or facilitated Track Two workshops rather than the participants of these workshops.
} 
the image one holds of out-groups, in-group esteem is enhanced as individuals within that group feel more positive about their own virtues, capabilities, and motivations and, by extension, more negative about the virtues, capabilities, and motivations of out-groups. In so doing, the psychological need for a positive self image is met, the individual's sense of well-being is enhanced, and social cohesion within the in-group is strengthened.

A number of well-known experiments confirm the tendency of people to behave with preference toward members of their own group and discriminate towards members of other groups, even when the basis of group membership was insubstantial (McGuire and Padawer-Singer 1976; Hogg and Turner 1985). Indeed, the so-called "minimal group paradigm" suggests that the mere act of telling an individual that he or she is part of a particular group, whether or not a previous relationship or common traits exist, is enough to trigger in-group favoritism and out-group bias (Tajfel, Billig, Bundy, and Flament 1971). Sherif, Harvey, White, and Hood's (1961) and Sherif's (1966) Robbers' Cave Experiment, where young boys were placed into competing groups at a summer camp and exhibited all the signs of in-group/out-group bias, is one of the earliest and perhaps well known of these studies and the basis for what was to become known as realistic group conflict theory. ${ }^{3}$

Recently numerous social scientists have critiqued some of the elements of social identity theory, even as they have supported its central foundations (Rubin and Hewstone 2004). A special issue of Political Psychology in 2004, for instance, was devoted to considering some of the more pressing challenges to social identity theory, such as why groups sometimes fully participate in and actively legitimate social systems in which their group has low-status; why intergroup conflict is not more rife in a world where diverse group identities are pervasive; and the degree to which individual differences and personality factors lead to different levels of out-group hostility within particular identity groups (Huddy 2004; Jost, Banaji, and Nosek 2004; Reicher 2004; Rubin and Hewstone 2004). Such critiques have led to the rise of system justification and social dominance theories (Jost et al. 2004; Sidanius, Pratto, van Laar, and Levin 2004).

Marilynn Brewer echoes some of these concerns in her work on the relationship between in-group identity and out-group hostility. Critiquing Sumner's theory of ethnocentrism (1906) upon which much of social identity theory rests, Brewer's work finds that out-group discrimination is not an automatic function of in-group favoritism, instead, out-group discrimination and hostility requires additional "social structural and motivational conditions that are not inherent in the process of group formation itself" (Brewer 2001:19).

Other scholars of social conflict have sought to refine social identity theory by noting that individuals do not belong only to one identity group, but rather to multiple identity groups and that the salience of those identities shifts depending on circumstance and setting (Northrup 1989). For instance, a group of Caucasian students may not be overtly aware of their identity as Caucasian until members of a different race join their group. Individuals, in other words, are most aware of those identities that they feel are under threat. This phenomenon and its consequences for the group and individual have been well-documented in research conducted on "stereotype threat" (Steele, Spencer, and Aronson 2002) and have also been used to explain why the salience of ethnic identity is

\footnotetext{
${ }^{3}$ Even though Sherif's experiment differed from social identity theory by emphasizing an additional condition necessary for conflict, namely competition over realistic interests, still the earlier stages of the experiment point to the effects of in-group/out-group division before the introduction of competition.
} 
greater within minority groups that have experienced significant levels of prejudice and victimization.

\section{Intractable Conflicts, Prejudice, and Social Contact}

A directly related stream of theory is found in the work of scholars researching prejudice. Allport defines prejudice as "an antipathy based upon a faulty and inflexible generalization. It may be directed toward a group as a whole or toward an individual because he is a member of that group" (1954:9).

Prejudice is one of the essential ingredients of intractable conflicts and an outgrowth of social identity formation. Members of adversarial groups in conflict perceive the members of the out-group as less "equal" or "human" and thus, ultimately justify acts of discrimination and violence towards them (Bar-Tal and Teichman 2005). Prejudice may also serve to justify material or resource inequalities disfavoring the members of the out-group. Bar-Tal argues that accumulated hostility between the groups as a result of conflict feed the continuation of conflict through sustaining mistrust and the "ethos of conflict" in a society (Bar-Tal 2000; Bar-Tal and Teichman 2005).

There seems to be a tension between the realistic group conflict theory and social identity theory, as scholars made a distinction between "pure prejudice" and antipathies resulting from "real conflict of interests" (Allport 1954:232). However, they are not necessarily mutually exclusive. As Allport argued: "Realistic conflict is like a note on an organ. It sets all prejudices that are attuned to it into simultaneous vibration. The listener can scarcely distinguish the pure note from the surrounding jangle" (1954:233). In conflict situations, the interplay between the affect-laden identities and unequal positions and interests defined along those group boundaries are intertwined (Bobo and Tuan 2006:45).

In any case, both forms of prejudice are important elements of social conflict because each brings an element of unwarranted prejudgment to social exchange with the other, whether conflicting interests are at stake or not (Forbes 1997:17). For example, regardless of the initial reason of the conflict, based on a real conflict of interest or not, as long as Turkish Cypriots continue to mistrust Greek Cypriots as a group, a negotiated agreement and its implementation is hard to achieve.

There is agreement in the literature (Allport 1954; Pettigrew, Fredrickson, Knobel, Glazer, and Ueda 1982; Duckitt 2003) that prejudice may unfold itself through three psychological processes: in cognitive structures and processes (e.g. beliefs and stereotypes), as affect (negative feelings), and as behavior (for example social distance, discrimination, and violence). Yet, there is disagreement among scholars about what better predicts prejudiced behavior. Categorization and stereotyping is an inevitable part of information processing and negative stereotypes are expressive of prejudiced behavior (Duckitt 2003:562). Yet, the primacy of negative stereotypes to negative affect in causing prejudiced behavior is being debated. For example, Fiske (1998) argues that negative affect towards the out-group is more central to prejudiced behavior than categorization and stereotyping. ${ }^{4}$

\section{Social Contact and Its Criticisms}

As shown above, lack of contact between groups promotes bias and prejudice and may lead to its institutionalization over time. Once institutionalized, lack

\footnotetext{
${ }^{4}$ There is also disagreement with regard to what causes prejudice. For a review of different theories explaining the sources of prejudice, see Bobo and Tuan (2006).
} 
of contact then reinforces negative attitudes and beliefs about the out-group, further solidifying the boundaries between the in-group and the out-group (Hewstone and Greenland 2000:140). As a remedy, the human relations movement advanced the theory that if lack of contact reinforces inter-group bias and prejudice, contact between the members of identity groups can be used to overcome it (Pettigrew 1986). As members of identity groups interact, their preconceived notion of the other is challenged, commonalities across groups are revealed while accentuated differences are minimized, and members of each group humanize each other.

Yet, empirical research over the past several decades has shown that contact does not always result in positive attitude change and reduction of inter-group bias. Indeed, in some situations, contact appears to perpetuate hostile attitudes towards the out-group. These findings prompted the delineation of conditions under which contact is likely to succeed in reducing prejudice and inter-group bias. These are: (i) where members of each group have equal status (professional, educational, etc.); (ii) where each group is working towards a common goal; (iii) where each group is cooperatively interdependent; and (iv) where group contact is supported by laws, customs, or institutions (Allport 1954:281; Pettigrew 1971, 1991). Cook (1978), Pettigrew (1971, 1986, 1991, 1998), Amir (1969, 1976), Sherif (1966), Smith (1994), and Powers and Ellison (1995) tested these conditions and found results that confirm their importance. For example, Sherif (1966) showed that contact between groups under the circumstances of competition and lack of common goals can easily create the dynamics leading to inter-group conflict and violence.

In addition to research confirming these basic conditions, several others suggested additional conditions for contact to result in positive attitude change. Cook (1978) suggested that the intimacy of contact and the direction and strength of in-group norms with regard to inter-group association should be added. Others suggested that active participation (Maoz 2005), commonlanguage, voluntary contact, prosperous economy (Wagner and Machleit 1986), and positive initial views (Yogev, Ben-Yehoshua, and Alper 1991) be added to the initial four conditions.

The expansion of conditions was criticized by Pettigrew (1998) for overburdening the theory. Pettigrew argued that these additional conditions are not essential for inter-group contact to succeed, but rather are conditions that facilitate contact in specific settings (Pettigrew 1998). An exception to these new conditions is the condition of a friendly environment (Pettigrew 1998:72). Pettigrew argued that friendship, generated through affective ties, is a key factor in reducing prejudice and must be included in the generic framework of contact hypothesis rather than as a facilitating factor.

The first line of criticism directed to the theory was concerning the overemphasis of the inter-personal (for example Hewstone and Brown 1986). Such criticisms focused especially on the "generalization" problem and called for a revision in the inter-personal contact theory by bringing the inter-group relations dynamics to the forefront. This critique argued that inter-personal contact is not effective in reducing inter-group prejudice and hostility if it fails to "generalize" the effects of inter-personal contact beyond the individual to the inter-group level (Abu-Nimer 1999:4).

The problem of "generalization of contact effects" led to further research. Pettigrew (1998:70) identified three types of generalization of contact effects beyond the immediate situation: generalization across situations, generalization from individual to group, and generalization from one out-group to another out-group. Research on the first of these, "across situation generalization," argued that repetition of the optimal contact situation in more than one situation is necessary (Pettigrew 1998:74). Yet, it is the second type of generalization, 
the generalization of the effects from the individual to the out-group level, that has presented the greatest challenge to researchers.

Recent experimental research on generalization from individual to inter-group level suggests several competing "strategies" as to how it can be realized. Brewer and Miller (1984) found empirical evidence supporting the strategy of "de-categorization." They argued that group memberships need to be made less salient during contact so that social categories become less rigid. Through de-categorization (the weakening of the group boundaries between the self group and the other group), people can "personalize" and "differentiate" the outgroup in general. When members gain an inter-personal focus (individuation) instead of a salient category identity, positive effects of contact can be generalized to new situations and to out-group in general (Brewer and Miller 1984:288-289).

Hewstone and Brown (1986) and Brown, Vivian, and Hewstone (1999) challenged Brewer and Miller's strategy of "de-categorization" and suggested that the counter strategy of "category salience" is more effective in generalizing the effects of contact beyond the immediate situation. In this strategy, maintaining the salience of group categories during inter-group contact, simultaneously with a pleasant encounter, promotes generalization better because the out-group member contacted is seen as "typical" or "representative" of the out-group (Brown et al. 1999:744). Typicality of the group member being contacted is especially considered important for generalization in the context of a "perceived homogenous" group (Brown et al. 1999:761). Thus, the second strategy changes the nature and structure of the inter-group relationship by keeping the saliency of group membership, rather than de-emphasizing group categories.

A third strategy is called the "common in-group identity model" (Gaertner, Mann, Murrell, and Dovidio 1989; Gaertner, Dovidio, Anastasio, Bachman, and Rust 1993) and suggests "recategorization" as an effective way of generalizing contact effects. In this model, the in-group and the out-group boundaries are merged under a more inclusive superordinate identity. Thus, in light of a newly formed common in-group identity, positive inter-group relations develop and bias and in-group and out-group categorization subsides.

A fourth and final strategy for generalizing contact effects from the individual to inter-group level is through gaining knowledge or observation of in-group/ out-group friendships (Wright et al. 1997 cited in Pettigrew 1998:75 and in Brown et al. 1999:761). Wright et al.'s empirical findings suggested that people who had knowledge or observation of in-group/out-group friendships indicate less prejudice and in-group bias towards the out-group than others. This strategy differs from the others in the sense that it puts emphasis on attitude change acquired without inter-personal contact.

Despite the overall picture which portrays competition between these alternative explanations for generalization from individual to inter-group level, Pettigrew (1998) argued that all three strategies (de-categorization, salient categorization, and recategorization) can occur sequentially. He argued that while de-categorization is a viable strategy during the initial stages of contact when anxiety is the dominant affect, salient categorization might be more important when contact is more established. On the other hand, recategorization can be regarded as the maximum reduction of prejudice, which is not easy to attain but ultimately possible (Pettigrew 1998:77).

Gonzalez and Brown (2003) also found evidence supporting the complementary application of generalization strategies. In a study testing four categorization strategies in a cooperative setting they found that all strategies were successful in not activating inter-group bias, but only the simultaneous activation of sub-group and superordinate categories (identities) resulted in the reduction of bias (Gonzalez and Brown 2003:210). As far as generalization is concerned, both of the two strategies, dual identity strategy (which activated both the sub-group cat- 
egory salience and a superordinate category) and the superordinate category strategy (recategorization) were found effective in generalizing positive effects of contact beyond the immediate situation. Thus, this research found support for both Gaertner et al.'s (1993) "recategorization" and Hewstone and Brown (1986), and Brown et al.'s (1999) “salient categorization" strategies under conditions of explicit cooperation. In other words, the distinct group identities remained salient within a superordinate group category.

A second line of criticism directed against contact hypothesis concerns its failure to fully describe the change process that results from contact (for example Bar and Bargal 1995; Maoz 2000). With regard to this criticism, Pettigrew stated that the contact theory requires an explicit specification of the process and suggested that inter-group contact results in attitude change through four kinds of processes (1998:70-73). These processes can be summarized as:

1. Learning about the out-group: Change may occur by generating new learning about the other that contradicts the existing stereotypes and attitudes.

2. Changing behavior: By changing the behavior first, dissonance will be formed between the prejudiced attitude and the new positive behavior. This will result in revision of the attitude. The more repeated the contact is in varied settings, the more likely that the revision of attitudes in line with the new behavior will take place.

3. Generating affective ties: A third process through which contact can trigger positive change is by forming strong affective ties and empathy with the out-group, intimacy, and inter-group friendship.

4. In-group reappraisal: Attitude change occurs by learning and revising attitudes about the in-group. New learning about in-group (for example the in-group is not homogenous or superior) leads to the reduction of in-group bias and favoritism and consequently leads to a "less provincial" view of out-group.

These four processes are closely linked to the research exploring attitude change. Attitude change can occur through cognitive, affective, or behavioral processes and don't have to have all three at the same time (Eagly and Chaiken 1998:272). Until recently research on attitude change has focused more on cognitive processes such as the link between attitude consistency and change (Eagly and Chaiken 1998). An important finding has been that people holding more extreme attitudes are more likely to resist change through social influence (Eagly and Chaiken 1998:287). As well, when attitudes are linked to self-defining values and reference groups, which is the case in most intractable conflicts, they are resistant to change. Recently, the role of affect in attitude change has been highlighted. Stangor, Sullivan, and Ford (1991) for instance argued that affect is the primary basis for attitudes towards out-groups and that affect is at least as strong as cognition in impacting attitudes.

Finally, a third criticism directed towards the contact hypothesis focused on the limitations of inter-personal contact and changing attitudes in situations of institutionalized inequalities and discrimination (for example Reicher 1986). In intractable conflicts, subjective elements of inter-group conflict are intertwined with structural inequality and discrimination (Azar 1990; Bobo and Tuan 2006). Lemish (cited in Abu-Nimer 1999) furthered this line of criticism and suggested that contact creates an illusion of a solution when the structural inequalities continue to exist and thus, it serves the interests of the dominant or the powerful group. The leading scholar of contact theory, Pettigrew, revisited the theory, suggesting in his later work that contact and education by itself are not sufficient remedies to prejudice (1986:172).

Table 1 below summarizes the theoretical discussion so far and indicates the original theory, its critics, and how critics have been addressed. 


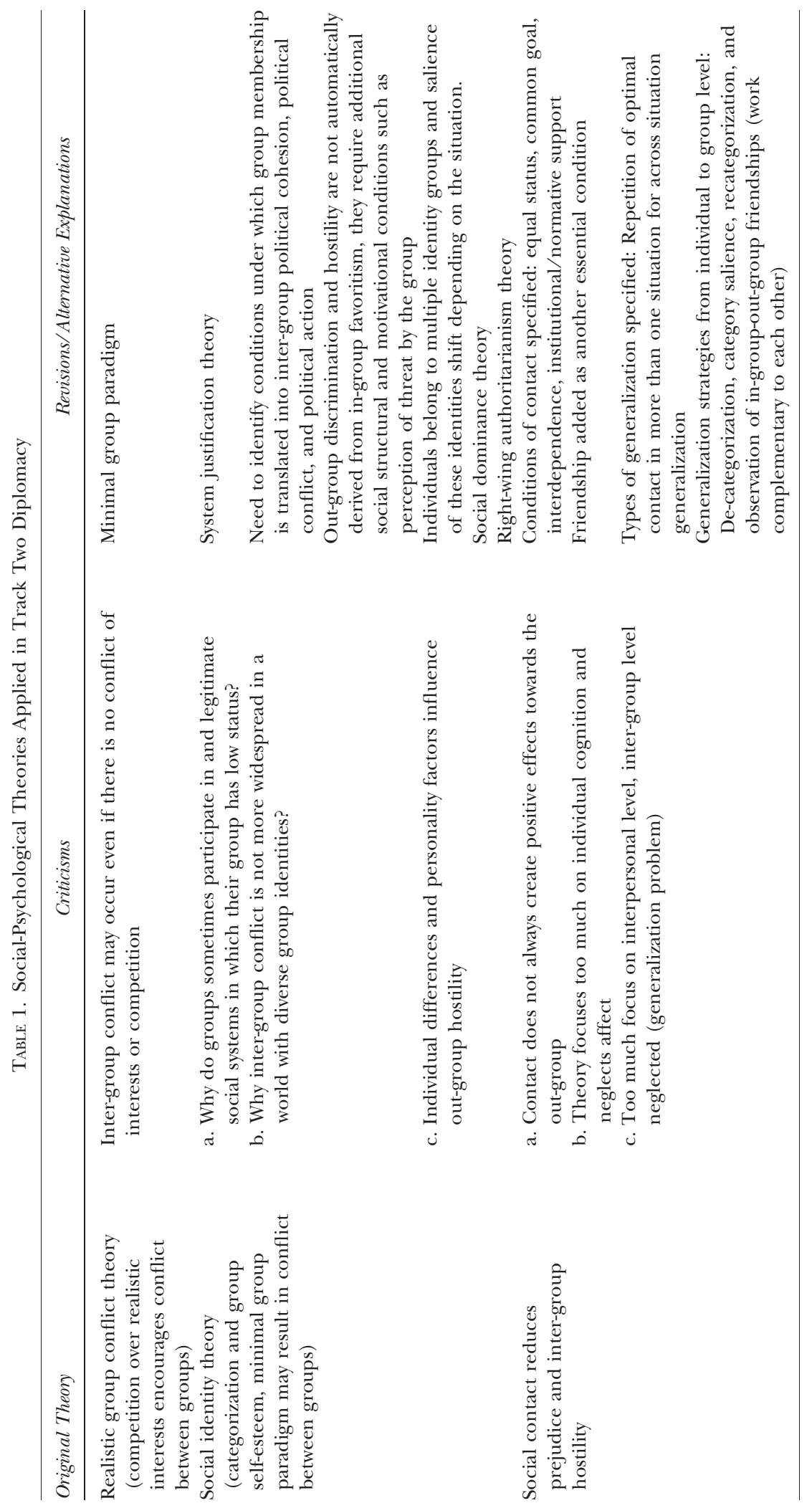




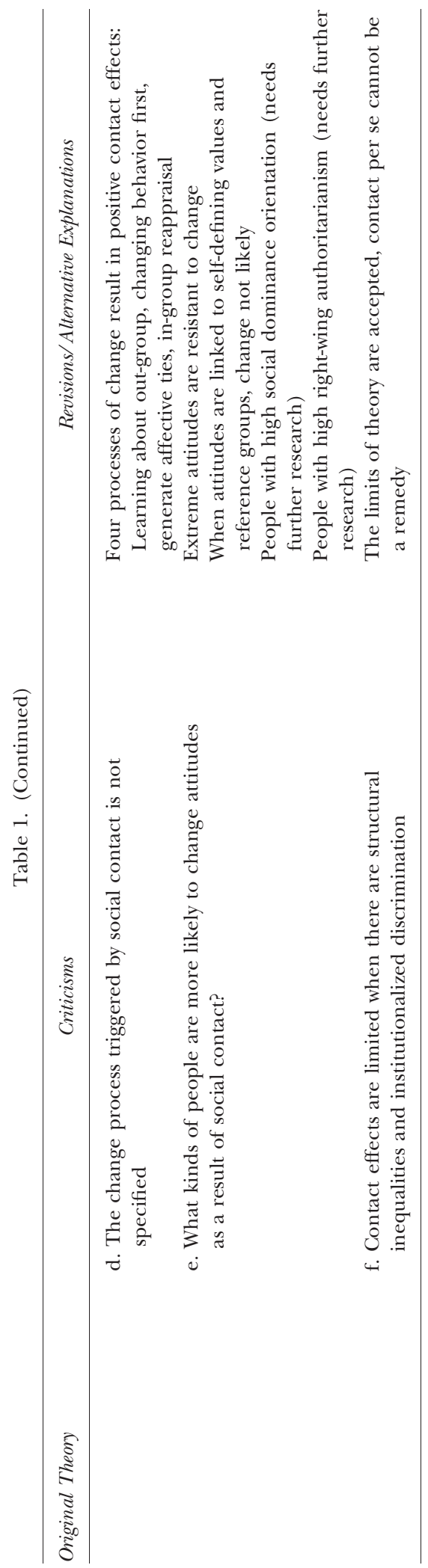




\section{Theory Applied: Transformation of Intractable Conflicts through Track Two Diplomacy}

Since the 1960s, social identity theory, research on prejudice, and social contact theory have been used to construct a wide variety of applied efforts to transform intractable conflicts. This section will review the most prominent of these applied traditions, Track Two diplomacy.

Track Two diplomacy (Montville 1987) has emerged in the past several decades as a supplement to traditional state-based diplomatic initiatives, particularly in conflict zones where intractable identity-based conflicts have proven resistant to official peacemaking efforts. A form of conflict transformation practice, Track Two diplomacy, involves the facilitated interaction of parties on each side of a conflict. Interactions can be structured to share conflict narratives, build understanding and trust, or even develop unofficial solutions to the conflict. Thus, among the varied goals of Track Two are to provide a safe, off-the-record venue for dialogue; to create the conditions necessary for formal agreements to "take hold"; increase communication, understanding and trust among polarized groups; break-down the stereotypes and dehumanizing cognitions that permit the partisans to wage the conflict destructively; and to develop consensus-based proposals that can be transferred to the Track One processes (Fisher 1997; Davies and Kaufman 2002; Saunders 2005).

Cuhadar (2009) has categorized Track Two activities along two dimensions: the type of representatives that are brought together for interaction, and the "stage" at which the conflict is being waged. Within the first dimension, Track Two efforts are differentiated by the background of representatives. The representatives range from political leaders who interact unofficially, to influential elites (for example newspaper editors, academics, leaders of civil society groups, political advisors), to people that represent grassroots organizations within specific communities (for example youth, religious leaders, women). Within the second dimension, Track Two activities are designed at various stages of conflict, from the preventive, pre-negotiation, and negotiation stages to post-conflict stage (Rubin, Pruitt, and Kim 1994; Kriesberg 2007).

Another useful distinction in understanding the types of Track Two diplomacy is to differentiate between outcome-focused initiatives and process-focused initiatives. While the former is designed to generate proposals that can be used or adopted in official policymaking and negotiation processes, the latter type has a priority to build relationships, trust, empathy, and mutual understanding among adversaries in order to prepare the groundwork for a widely supported peace to take hold. An initiative can incorporate both goals or adopt only one of them, but both approaches have been widely used. To give an example, discussions between unofficial representatives of Israelis and Palestinians resulted in the 2003 Geneva Accords, which outlined a "final status" solution to the IsraeliPalestinian conflict. At the other end of the spectrum, the organization Seeds of Peace provides, among other things, the chance for young Israelis and Palestinians to interact at a summer camp where they learn about each other, leadership, and coexistence.

\section{Track Two Critiques: The Gap between Theory and Practice}

As noted at the outset of this paper, the field of conflict transformation practice known as Track Two diplomacy evolved in the 1960s as an applied extension of social-psychological theories regarding inter-group conflict. Since that time applied work has evolved in many different directions, very often without much consideration of the theories that are located at the roots of this practice or of how core theoretical assumptions have been challenged and refined in recent years. 
The following section of this paper aims at reintroducing the link between social-psychological theory on inter-group conflicts and the practice of Track Two diplomacy. We identify three areas where advances in theory, reviewed in the first half of this paper, have not been adequately incorporated into current Track Two practice: (i) the conditions under which contact between the members of adversarial groups works effectively and how the process of achieving positive outcomes takes place; (ii) the generalization of the effects of contact from interpersonal to inter-group level and the debate on the transfer of interpersonal outcomes of the Track Two initiatives to a wider context; (iii) the "unit of analysis problem" in Track Two which continuously shifts between the individual and societal levels. The assessment of each of these "gaps" between theory and practice relies on several research projects that the authors have undertaken in the last several years on Israeli-Palestinian and Greek-Turkish Track Two initiatives. These studies included personal or focus group interviews with more than 40 Track Two practitioners.

\section{Gap I: Understanding and Implementing the Theories of Change in Track Two Work}

A theory of change is important in understanding, reflecting upon, and planning which process leads to change in a Track Two activity. It is a construct used in program evaluation to help project designers better understand the causal assumptions they make about the problem that they are addressing, the goals of their project, and the activities they design to achieve those goals. It can be defined as "the causal processes through which change comes about as a result of a program's strategies and actions"' (Weiss 1998:55; Shapiro 2005:1).

For example, in 2005 and 2006 the authors of this paper and their colleagues conducted three focus group meetings, the first two with a group of Israeli and Palestinian peace practitioners, and a third one with practitioners from the broader Middle East, Greece, Turkey, and the Balkans. The purpose of the meetings was to understand what kind of theories of change practitioners use in their conflict resolution projects that were based on contact between the adversaries. The projects varied in terms of participants, goals, conflict stages, activities etc. Some practitioners used a range of tools and strategies together with contact such as media, summer camps, and conflict resolution trainings. We observed that an important number of practitioners have been undertaking their activities without formulating a theory of change, which maps the relationship between their activities and how these activities would lead to their expected outcomes in these projects. For instance, one organization carried out activities that brought together Greek and Turkish teenagers in a summer camp and had them work on various common tasks, but did not explain the rationale of why and how this activity, and especially the particular common task chosen, would lead to a positive attitude change (which was their stated expected outcome). Another organization that aimed at creating a pluralist society and strong citizenry offered basic mediation training for the representatives of adversary groups in an interactive setting, but did not specify the rationale about how these trainings would contribute to this goal.

Another common problem that we observed related to theory of change was that some practitioners did not clearly articulate what their expected outcome was, but rather mentioned an inflated and generic list with numerous overarching goals. For instance, one organization working with the Greek and Turkish university students stated the goals of creating a network of young leaders, strengthening civic dialogue, building a pluralist society and strong citizenry, and deepening the Greek-Turkish peace efforts. In order to achieve all of these macro goals, they undertook three weekend-long interactive workshops which included several hours of mediation training, structured and unstructured contact time, lectures on the conflict history, lectures on theories of conflict and peace, and a 
paper to be written by Greek-Turkish teams. The link between these activities and how they would achieve each of the stated goals was not specified, nor was the goal for the initiative clearly and realistically articulated.

\section{Policy Recommendation}

Those engaged in conflict transformation projects should, at the outset of each new project, "map" the rationale linking the specific activities to the goals of the initiative. In the next paragraphs, we present a list of propositions drawn from the previous theoretical discussion in social and political psychology that practitioners can use to guide this process.

\section{Identify and Apply the Optimal Contact Conditions}

As we discussed in the previous section, the four conditions of contact are necessary to achieve positive outcomes. Creating a friendly environment, bringing participants that have equal group status within the situation, having them work towards a common goal in a cooperative environment are essential conditions for an effective contact situation.

Most Track Two practitioners are successful in establishing the optimal conditions of contact, especially creating a friendly and cooperative environment, and having the participants work towards a common goal. However, such decisions are sometimes made intentionally and other times unintentionally. Developing awareness about these conditions would make these initiatives more effective.

Equal group status is one of the optimal contact conditions that requires special attention. Often times, conflict takes place between asymmetrical parties. For example, Maoz (2004) in her analysis of coexistence initiatives among Jews and Arabs in Israel used equal status as "symmetry between members of both groups in active participation in the encounter." On the other hand, Cuhadar (2009) referred to equal status as symmetry of the Israeli and Palestinian participants in terms of their degree of connectedness with the official circles. Overall, asymmetry, in either sense, worked against obtaining effective outcomes from the Track Two activity (Maoz 2004; Cuhadar 2009:656). Therefore, practitioners should strive to achieve both types of symmetry while designing their initiatives.

\section{Repetition is Necessary for Sustainable Attitude Change and Generalization of Contact Effects Across Situations}

Only after optimal contact is repeated in numerous situations, positive results become more likely and sustainable. Repetition is a key part of the process both when behavioral and cognitive change is targeted. Therefore, funders and organizers of Track Two initiatives should aim for a series of contact situations with the same people rather than a one-shot event. Additional follow-up activities in the societies of conflict parties, after the re-entry of the participants, are also critical in terms of repeating the contact situation in a more "natural" setting in order to maintain the sustainability of the contact effects. As discussed in the previous section, research on the generalization of contact effects across situations suggests that optimal contact with the "out-group" should be repeated in more than one situation in order for change to be generalized from the immediate encounter to other similar situations. Furthermore, research on the sustainability of peace efforts draws attention to the importance of continuous interventions by the third party for the reinforcement of attitude change, especially in order to downsize the negative effects of a violent conflict environment (Rosen 2006).

Recently, there has been a growing awareness among the practitioners with regard to creating "natural" environments in the local setting that are 
conducive to repeating the pleasant contact situation experienced elsewhere. These serve as support groups in the midst of the conflict and aim at easing the "re-entry" problem. A good example of such an effort can be given from Seeds of Peace and its two local programs; the "Delegation Leaders Program" and the local meeting and activity house built in Jerusalem for the Maine summer camp teenagers to continue to meet after they return home. The delegation leaders participating in the summer camp continue to meet in their home countries amongst themselves and also with their counterparts to continue their activities.

\section{Consider the Fact that Contact Effects can be Achieved Via Different Processes (Cognitive, Affective, or Behavioral)}

We mentioned four kinds of processes suggested by Pettigrew that facilitate attitude change through contact. Although there is not an explicit agreement among researchers as to whether all four are necessary or if one of these processes is more important than others, Track Two practitioners should know which process they are using in their interventions. For instance, if they are targeting change through cognitive means by providing new knowledge, they should be aware that this may not be sufficient by itself to generate change in attitudes towards the "other" or the conflict, especially if they are dealing with people who hold extreme attitudes, or the results will vary depending on the belief complexity of the representatives. Also, repetition of the new knowledge about the out-group, contact with "typical" members of the out-group, and high inconsistency between the out-group's behavior and the stereotype held about the members of that group could help facilitate change through cognitive means.

There are numerous examples of initiatives that target attitude change through cognitive processes. Most of the peace workshops for instance aim at attitude change through new learning by teaching a peace and human rights curriculum to students while they are in contact with an out-group. During the workshops the facilitators often provide information that contradicts the existing knowledge about the out-group members and the conflict. Training representatives of groups in conflict resolution skills similarly targets change through cognitive processes as well as behavioral adjustment.

If behavioral adjustment is adopted as the main process to generate attitude change, change in attitudes will most likely follow the behavioral change when the dissonance between the old attitude/belief and the new behavior is resolved. Even though there may be individual differences in when and how this gap is resolved, third-party practitioners should be available for the participants to facilitate and support this process. Several of the Track Two initiatives, especially those that incorporate training in conflict resolution skills or initiatives held with children and teenagers follow this model. For instance, young people are required to participate in cooperative games and activities as part of a summer camp based on social contact in various initiatives. In one of these initiatives we observed, Greek and Turkish Cypriot teenagers are placed into situations where they act as a group and cooperate in order to achieve a difficult common task such as climbing a mountain.

\section{Generating Friendship and Attitude Change Via Affective Processes is No Less Important}

No less than cognition, emotions play a role in generating attitude change. Positive emotions like empathy and a friendly environment that harbors positive

\footnotetext{
${ }^{5}$ Re-entry refers to the entry of the participants of a Track Two activity into their societies after going through a series of meetings usually held in isolated and conflict-free environments.
} 
affect may trigger change. For Stangor et al., affect is the primary basis for attitudes towards out-groups (cited in Eagly and Chaiken 1998:278). In addition, research shows that direct experience with an attitude object (a representative of the adversarial group in this case) yields emotional responses as well as information towards it (Eagly and Chaiken 1998:279). Therefore, practitioners should also take affect into consideration as part of the change process.

Affect is especially a strong component of Track Two initiatives carried out with young people and children. Long-term relationships are more likely to result in a successful change process rather than initial acquaintanceship with the members of the out-group. For instance, Genc (2006) found that despite the haphazard training content of a Greek-Turkish youth project, the friendships developed during the process as a result of intensive social time together and the common tasks assigned to mixed ethnic groups which asked for their cooperation were instrumental in achieving positive outcomes. High anxiety experienced during the initial encounter left its place successfully to intimate friendships among the participants. However, if high anxiety and threat continue after the initial contact, it might impede the process of positive change.

The designing of the social time together during the initiatives is extremely important in facilitating the generation of affective ties. The social time should allow for self-disclosure and the discovery of "commonalities" across categories. Many of the Track Two participants we interviewed during the project primarily recall their socialization experiences and the friendships they built during this time.

\section{Working with the In-Group Alone Should not be Ignored or Underestimated}

By working solely with the in-group, Track Two organizers and facilitators can generate attitude change as well. Attitude change towards the out-group may be a result of a new insight about the in-group. This process of change can be especially relevant when encounters between the two groups are difficult to organize due to physical separation or funding problems. The "Delegation Leaders Program" of the Seeds of Peace can again be given as a good example which uses this kind of process for change. The program promotes the organization of activities targeting the "in-group" only within their own communities. Another example can be given from the workshops carried out by Benjamin Broome in Cyprus in early 1990s (Broome 2005). As a facilitator he started the work with each identity group separately and then with the two groups together.

\section{Gap II: Beyond the Workshops and Thinking about Transfer Strategies}

The second gap between the theory and practice in Track Two diplomacy is related to the transfer strategies. The theoretical discussion among the contact scholars with regard to the generalization of contact effects from the individual to inter-group level is relevant to address this gap. This gap addresses the question: How can the changes that take place in the immediate participants (microlevel) be transferred to settings beyond the immediate participants (macro-level)?

The initial expectation of Track Two scholars was that once the relations between the participants in the workshops improve and their perceptions of the conflict change, the results would automatically "transfer" to macro level. This process has proven to be more complicated and is hurdled with several challenges. Several scholars working on Track Two diplomacy discussed challenges pertaining to the transfer of effects and suggested models to facilitate transfer (for example Mitchell 1993; Fisher 1997; Dassa Kaye 2007; Cuhadar 2009). How- 
ever, scholars particularly focusing on Track Two did not draw parallels between the transfer problem in Track Two and the generalization problem articulated in research on social contact despite the similarities between the two.

\section{Policy Recommendations}

There are two types of challenges concerning transfer (a.k.a. generalization) beyond the immediate workshops on which scholar-practitioners can work. First, consider how representatives of adversarial groups generalize their attitude change to the whole "out-group" beyond the individuals they encountered in the workshop. Second, consider how the effects and outcomes of the workshops spill over to other people in their in-group (that is society and decision-making circles). We address both of these challenges faced by the Track Two practitioners with reference to the research discussed earlier concerning the generalization of contact effects. Research on the generalization of contact effects can contribute to the designing or implementing better "transfer strategies" in Track Two practice. By "transfer strategies" we refer to any strategy planned or used by Track Two practitioners to transfer the outcomes of the Track Two workshops to the macro-level.

During the three workshops with various practitioners, we asked the practitioners whether they planned any "transfer strategies" or not and which ones were used (either planned or unplanned). We found out that Track Two initiatives use a range of strategies to generalize the workshop effects beyond the participant group. Some of these aim to influence large groups like community organizations, the media, and public opinion; others target smaller groups like decision-makers, political advisors, and negotiators. ${ }^{6}$ Among the common transfer strategies we identified were: Sending artifacts (for example consensusbased recommendations, technical information) to policymakers; selecting the "right" participants; conducting a media campaign; establishing a functional role for the group during and after the workshops (for example epistemic community, policy advisory); forming an ongoing network enabling policymakers to reach a substantive agreement later; modeling and demonstrating that there are people on the other side with whom agreements might be reached; and using public communication in order to organize a "cognitive assault on existing myths."

One critical strategy preferred by many in practice is selecting the "right" people for the workshops. What is understood by "right" people depends on the practitioner, but usually they refer to influential, representative, or sometimes skilled people. "Influential" people are usually defined as those that are politically connected, close to decision makers, or are opinion leaders (for example academics, newspaper editors, community leaders). These people are thought to have better potential in transferring the effects and outcomes of the Track Two workshops beyond the immediate setting. Yet, research concerning the generalization of contact effects implies that much more is needed for successful transfer than just including opinion molders. In order to plan a more effective interaction, in addition to the political and social backgrounds of the participants, practitioners also need to find out about several psychological factors concerning the participants, like their attitude strength and group identification. While selecting people who are predisposed to dialogue or are highly moderate in their attitude towards the out-group may be effective in the initial stages of meetings, it has limits for generalization in the long-term. Such people

\footnotetext{
${ }^{6}$ The Geneva Accords, initiated in order to sway Israeli and Palestinian public opinion is an example of the former, the use of Track Two as a mechanism to facilitate the Oslo peace process is an example of the latter.
} 
may be able to successfully follow a "de-categorization" strategy by improving inter-personal relations and attitudes more quickly, however, the generalization effects are limited because they are often not seen as "typical" members (representing the salient group categories) by the members of the "out-group" they encounter with or by the people they interact with outside the Track Two initiative. Thus, this limits both the generalization of effects to the whole out-group and generalization of effects to the others in the in-group.

Overall, the "de-categorization" strategy, when used alone or when used in all stages of contact, may be ineffective for generalization. Even if making "group membership" less salient is a generalization strategy adopted by some organizing third parties during the initial meetings in order to prevent anxiety and conflict in the workshops, as the workshops proceed it should pave the ground to other strategies that will be more effective. The following quotes are examples from interviews with an Israeli and a Palestinian Track Two participant respectively that suggest such problems with the de-categorization strategy. They especially highlight the perception of the "untypical" nature of people with whom they interacted. Both can be seen as examples of lack of generalization of positive attitudes to the whole out-group:

"...What we received there was crème de la crème, very educated people only. I
didn't have problem communicating with them [referring to the Palestinians in
the group only]. They are free, completely Westernized, good sense of humor."

and the Palestinian participant:

\begin{abstract}
"There is a difference between an [Israeli] academic and diplomat. I learned to be a diplomat in Track Two. When you are a diplomat you don't allow the other side to lure you with their good looks. If you become friendly with them as a person, then you develop human bonds which make you forget the concrete clash of interest. It blinds you to the end result. If you are a real diplomat, you have to be careful about being seduced by the charms of the other side.... The Israeli academics we have dialogue with are not the same Israelis we negotiate with. The Israelis we have dialogue with are Israelis with whom we have common ideological understandings. [Others] are usually [those] who don't share the same worldviews, they are very suspicious, they are part of the establishment and people we have differences with.",
\end{abstract}

There are numerous Track Two initiatives that follow the de-categorization strategy only by recruiting people whose group membership is not "salient." However, the ongoing conflict on the ground, which exacerbates the re-entry problem for representatives, makes de-categorization less likely to succeed. Furthermore, the expectation from the representatives in some Track Two projects to convince the skeptics and make input into the negotiations creates further dilemmas for them as mentioned in the second quote.

To recall the research in political psychology on generalization, Track Two practitioners are more likely to succeed if they use "salient categorization" as a strategy, in which people in contact are perceived as "representative" or "typical" of the dominant group identity. Third parties should design workshops which maintain group membership salience while involving a more representative sample of each group's members in the Track Two initiatives. This strategy is especially important for outcome-oriented Track Two initiatives that aim to influence negotiations and mainstream public opinion. Several of the IsraeliPalestinian Track Two initiatives attempted to implement this strategy, such as in an initiative that brought together the settlers and Palestinian refugees. Some others also deliberately expanded the meetings to political groups other than the moderates that were typically involved in earlier contacts with Palestinians. 
However, still many other initiatives continued their activities only with those that are seen "atypical" by their in-group.

Recent research on the generalization of contact effects also shows that "dual identity strategy" (the combination of salient categorization and recategorization under a superordinate category) or "recategorization strategy" by itself are quite effective in generalizing positive interpersonal change to the whole out-group. This means that not only salient categorization, but also recategorization can be used simultaneously as a strategy to generalize the effects of Track Two workshops. Even though recategorization is more difficult to achieve and requires contact across an extended period of time, examples of "dual identity strategy" can still be found in the Track Two practice. For example, Cuhadar (2009) reports the successful formation of a joint Israeli-Palestinian water experts group which emerged as a result of nine years of friendly contact and joint work among a group of Israeli and Palestinian water professionals sponsored by the Truman Institute and the Palestine Consultancy Group. The group members maintained their separate salient group identities as Israelis and Palestinians and at the same time succeeded in forming a superordinate group identity based on their professional group memberships as "water professionals" who share the same views and values about water regardless of their national group memberships.

However, it should be noted that "recategorization" is difficult to maintain as a strategy if the situation becomes polarized and inter-group conflict intensifies. Such a situation becomes difficult to generalize positive attitudes to the whole out-group. For instance, as the violence intensified, it became difficult for the Palestinian participants to continue their contact with Israelis and to generalize their positive attitudes to other members of the out-group as well as those with whom they are in contact. This resulted in the limitation of positive attitudes only to the recategorized "new" in-group, for example the water experts only, rather than to the whole national group. The following quote is an illustration from a Palestinian participant we interviewed:

\footnotetext{
"I felt the Israelis who worked with us really wanted to solve the problem. They are good intentioned and open minded people. I felt that we could solve the problem for the welfare of the two sides with them, if we had people [on the other side] who think logically like this. They are not fanatics. If we continued with these people, we could have achieved something.'
}

A final research finding from contact theory that is relevant to transfer strategies is concerned particularly with the use of media and public campaigns to transfer the effects of workshops. To recall the previous discussion in the paper, Wright et al. (cited in Pettigrew 1998:75) showed that those who know of or observe ingroup/out-group friendships show less prejudice and in-group bias than those who do not. This has the following repercussion for Track Two practitioners: Public display of joint and cooperative work and activities by the Track Two participants in media or in other public domains has a potential to influence those who were not in contact. However, other research suggests that attitudes based on direct experience with an attitude object are stronger as opposed to attitudes acquired through indirect experience (Eagly and Chaiken 1998:279). Thus, the use of media as a transfer strategy, although effective to a degree, may still be less effective than direct contact and could be used as supplementary.

\section{Gap III: The Unit of Analysis Challenge}

Social identity theory and contact theory are theories which take as a starting point the notion that group identity is superordinant to individual identity in situations of intractable conflict. Social identity theory, in particular, assumes that 
in-group/out-group hostility is a function of the clustering of people into distinct identity groups where the need for self-esteem motivates inter-group comparisons that result in-group favoritism and out-group bias. Social identity theory, theories of prejudice and stereotyping, and contact theory are therefore, all theories that take the group as the unit of analysis of interest when exploring conflict. Similarly, Track Two practice takes the whole identity group as the basis for its planning and selects participants based on their affiliation with a group.

But members of particular identity groups are also individuals with distinct personalities, personal constructs, and other individual-unit characteristics that differentiate them from other members of their in-group. To assume that each member of a particular identity group is interchangeable with every other member of that group (that is, will behave in the same way from situation to situation) may lead Track Two practitioners to overemphasize the role of group membership in guiding perception and action while underemphasize the role of individual personality. Third-party intermediaries that arrange Track Two encounters are themselves shaped by individual-level personality characteristics that have a profound impact on the direction that they take. Why should the individual personalities of the participants in Track Two exchanges have any less of an effect?

\section{Policy Recommendation}

Given this observation, Track Two practitioners may do well to consider how individual personalities may lead one member of a group to understand and respond to inter-group contact in one way, while another member of the same group may understand and respond to an inter-group encounter in another way.

This observation leads us to one final issue. The identities which become salient to the individual as they navigate the social world can change from context to context. As noted earlier, the context in which individuals find him or herself may trigger the emergence of one identity as being most salient at that moment over others. The following quote is an example from a Palestinian Track Two participant, who was imprisoned by the Israeli security officials and held quite negative attitude towards them, suggesting that his ideological identity becomes more important than his national identity in a particular Track Two context:

\footnotetext{
"I already had good friends [on the Israeli side] who were very marginal in the Israeli society. I get along better with them than with many in the Palestinian society because ideologically we are very close to each other so we forget about our ethnicity."
}

How then can Track Two practitioners know what identities are at play in the contact encounters that they arrange? Practitioners may assume that the identity cleavages generated by inter-group contact break along the "ethnic" (racial, national, etc.) lines that they have organized their work around, however, what if Track Two exchanges trigger other identities within individual participants? The fact that one can make a distinction within in-groups between "doves" and "hawks" is itself an indication that within-group identity distinctions play a powerful role in contact outcomes. How can practitioners better understand the emergence of these within-group identities and construct Track Two encounters that are fluid enough to accommodate and work with them? Unlike the first two gaps we discussed in this paper, this gap is hardly addressed by the students and practitioners of Track Two. The theoretical work on identity as a "shifting target" instead of a fixed attribute of people is also relatively less established to guide practice. Further research needs to be conducted to answer such questions 
and this research can highly benefit from other theories in social-psychology in explaining prejudice and conflict by looking at individual differences such as social dominance orientation, right-wing authoritarianism, and attitude strength.

\section{Conclusion}

The field of social-psychology has made critical inroads toward our understanding of the dynamics that foster inter-group hostility, stereotyping, and prejudice. Over the past 30 years many of these insights have been applied by practitioners as they have experimented with various forms of inter-group interaction under the rubric of Track Two Diplomacy. Although theoretical work on the socialpsychology of inter-group conflict has steadily advanced over the past three decades, a corresponding evolution of applied practice has not occurred. This gap between the evolution of theory and the evolution of practice is in some ways quite understandable given that social-psychological theories about intergroup conflict are more easily tested in the laboratory than in real world settings. Narrowing this gap cannot be achieved without encouraging another form of Track Two contact: that between academic researchers and applied practitioners. We hope that this paper serves as a starting point for such a dialogue.

\section{References}

Abu-Nimer, M. (1999) Dialogue, Conflict Resolution and Chage: Arab-Jewish Encounters in Israel. New York: State University of New York Press.

Allport, G. (1954) The Nature of Prejudice. Cambridge, MA: Perseus Books.

Amir, Y. (1969) Contact Hypothesis in Ethnic Relations. Psychological Bulletin 71: 319-342.

Amir, Y. (1976) The Role of Inter-group Contact in Change of Prejudice and Ethnic Relations. In Towards the Elimination of Racism, edited by P. A. Katz. New York: Pergamon.

Azar, E. (1990) The Management of Protracted Social Conflict: Theory and Cases. Dartmouth, England: Aldershot.

Bar, H., And D. Bargal. (1995) Living with Conflict: Encounters between Jewish and Palestinian Youth. Jerusalem, Israel: The Jerusalem Institute for the Study of Israel (in Hebrew).

Bar-Tal, D. (2000) Shared Beliefs in a Society: Social Psychological Analysis. Thousand Oaks, CA and London, UK: Sage Publications.

Bar-Tal, D., And Y. Teichman. (2005) Stereotypes and Prejudice in Conflict: Representations of Arabs in Israeli Jewish Society. Cambridge: Cambridge University Press.

Вово, L. D., And M. Tuan. (2006) Prejudice in Politics: Group Position, Public Opinion, and the Wisconsin Treaty Rights Dispute. Cambridge MA: Harvard University Press.

Brewer, M. (2001) In-group Identification and Inter-group Conflict. In Social Identity and Inter-Group Conflict Reduction, edited by R. Ashmore, L. Jussim, and D. Wilder. Oxford: Oxford University Press.

Brewer, M.B., And R. Brown. (1998) Inter-Group Relations. In The Handbook of Social Psychology, 4th edition, Vol. 1, edited by D. Gilbert, S. Fiske, and D. Lindzey. Boston: McGraw-Hill.

Brewer, M. B., AND N. Miller. (1984) Beyond the Contact Hypothesis: Theoretical Perspectives on Desegregation. In Groups in Contact: The Psychology of Desegregation, edited by N. Miller, and M. Brewer. New York: Academic Press.

Broome, Benjamin. (2005) Building Bridges Across the Green Line. Lefcosa: UNDP.

Brown, R. (2000) Social Identity Theory: Past Achievements, Current Problems and Future Challenges. European Journal of Social Psychology 30: 745-778.

Brown, R., J. Vivian, And M. Hewstone. (1999) Changing Attitudes Through Inter-group Contact: The Effects of Group Membership Salience. European Journal of Social Psychology 29: 741-764.

Соoк, S. W. (1978) Interpersonal and Attitudinal Outcomes in Cooperating Interracial Groups. Journal of Research and Development in Education 12 (1): 97-113.

Cuhadar, E. (2009) Assessing Transfer from Track Two Diplomacy: The Cases of Water and Jerusalem. Journal of Peace Research 46 (5): 641-658.

Dassa Kaye, D. (2007) Talking to the Enemy: Track Two Diplomacy in the Middle East and South Asia. Santa Monica, CA: RAND Publications. 
Davies, J., And E. Kaufman, Eds. (2002) Second Track/Citizen's Diplomacy. Lanham, MD: Rowman and Littlefield Publishers.

Duckitt, John. (2003) Prejudice and Inter-group Hostility. In Oxford Handbook of Political Psychology, edited by D. Sears, L. Huddy, and R. Jervis. Oxford and New York: Oxford University Press.

Eagly, Alice, and Shelly Chaiken. (1998) Attitude Structure and Function. In The Handbook of Social Psychology, 4th edition, Vol. 1, edited by D. T. Gilbert, S. T. Fiske, and G. Lindzey. New York: McGraw-Hill.

Fisher, R. (1997) Interactive Conflict Resolution. Syracuse, NY: Syracuse University Press.

Fisher, R. (2005) Paving the Way: Contributions of Interactive Conflict Resolution to Peacemaking. Lanham, MD: Lexington Books.

Fiske, S. T. (1998) Stereotyping, Prejudice, and Discrimination. In Handbook of Social Psychology, 4th edition, Vol. 2, edited by D. T. Gilbert, S. T. Fiske, and G. Lindzey. New York: McGraw-Hill.

Forbes, H. D. (1997) Ethnic Conflict: Commerce, Culture, and the Contact Hypothesis. New Haven, CT: Yale University Press.

Gaertner, S. L., J. Mann, A. Murrell, and J. F. Dovidio. (1989) Reducing Inter-Group Bias: The Benefits of Recategorization. Journal of Personality and Social Psychology 57: 239-249.

Gaertner, S. L., J. F. Dovidio, P. A. Anastasio, B. A. Bachman, and M. C. Rust. (1993) The Common In-group Identity Model: Recategorization and the Reduction of Inter-group Bias. In European Review of Social Psychology, Vol. 4, edited by W. Stroebe, and M. Hewstone. Chichester: John Wiley.

Genc, G. O. (2006) Evaluating Peacebuilding Initiatives Using Multiple Methodologies: Lessons Learned from a Greek-Turkish Peace Education Initiative. Unpublished MA Thesis, Istanbul: Sabanci University.

Gonzalez, R., And R. Brown. (2003) Generalization of Positive Attitude as a Function of Subgroup and Superordinate Group Identifications in Inter-group Contact. European Journal of Social Psychology 33: 195-214.

Hewstone, M., And R. J. Brown. (1986) Contact is Not Enough: An Inter-Group Perspective on the Contact Hypothesis. In Contact and Conflict in Inter-Group Encounters, edited by M. Hewstone, and R. J. Brown. Oxford: Blackwell.

Hewstone, M., And K. GReEnland. (2000) Inter-Group Conflict. International Journal of Psychology 35: 136-144.

Hewstone, M., M. Rubin, And H. Willis. (2002) Inter-Group Bias. Annual Review of Psychology 53: $575-604$.

Hogg, M. A., And J. C. Turner. (1985) Interpersonal Attraction, Social Identification, and Psychological Group Formation. European Journal of Social Psychology 15: 51-66.

Huddy, L. (2004) Contrasting Theoretical Approaches to Inter-group Relations. Political Psychology 25 (6): 947-967.

Jost, J. T., M. R. Banaji, And B. A. Nosek. (2004) A Decade of System Justification Theory: Accumulated Evidence of Conscious and Unconscious Bolstering of the Status Quo. Political Psychology 25 (6): 881-919.

Kelman, H. (1995) Contributions of an Unofficial Conflict Resolution Effort to the Israeli-Palestinian Breakthrough. Negotiation Journal 11: 19-27.

Kriesberg, L. (2007) Constructive Conflicts. Lanham, MD: Rowman and Littlefield Publisher.

Maoz, I. (2000) An Experiment in Peace: Reconciliation Aimed Workshops of Jewish-Israeli and Palestinian Youth. Journal of Peace Research 37 (6): 721-736.

Maoz, I. (2004) Coexistence is in the Eye of the Beholder: Evaluating Inter-group Encounter Interventions Between Jews and Arabs in Israel. Journal of Social Issues 60 (2): 437-452.

Maoz, I. (2005) Evaluating the Quality of Communication between Groups in Dispute: Equality in Contact Interventions between Jews and Arabs in Israel. Negotiation Journal January: 131-146.

McGuire, W. J., And A. Padawer-Singer. (1976) Trait Salience in the Spontaneous Self-Concept. Journal of Personality and Social Psychology 33: 743-754.

Mitchell, C. (1993) Problem Solving Exercises and Theories of Conflict Resolution. In Conflict Resolution: Theory and Practice, edited by Dennis Sandole, and Hugo van de Merwe. Manchester: Manchester University Press.

Montville, J. (1987) The Arrow and the Olive Branch: A Case for Track Two Diplomacy. In Conflict Resolution: Track Two Diplomacy, edited by J. McDonald, and D. Bendahmane. Washington, DC: Foreign Service Institute, US Department of State.

Northrup, T. A. (1989) The Dynamic of Identity in Personal and Social Conflict. In Intractable Conflicts and Their Transformation, edited by L Kriesberg, T. A. Northrup, and S. J. Thorson. Syracuse, NY: Syracuse University Press. 
Pettigrew, T. (1971) Racially Separate or Together? New York: McGraw Hill.

Pettigrew, T. (1986) The Inter-group Contact Hypothesis Reconsidered. In Contact and Conflict in Inter-group Encounters, edited by M. Hewstone and R. Brown. Oxford: Basil Blackwell.

Pettigrew, T. (1991) Advancing Racial Justice: Past Lessons for Future Use. In Opening Doors: Perspectives on Race Relations in Contemporary America, edited by H. J. Knopke, R. J. Norrell, and R. W. Rogers. Tuscaloosa: University of Alabama Press.

Pettigrew, T. (1998) Inter-group Contact Theory. Annual Review of Psychology 49: 65-85.

Pettigrew, T., G. Fredrickson, D. Knobel, N. Glazer, and R. Ueda. (1982) Prejudice. Cambridge, MA: Harvard University Press.

Powers, Daniel A., And C. G. Ellison. (1995) Interracial Contact and Black Racial Attitudes: The Contact Hypothesis and Selectivity Bias. Social Forces 74: 205-226.

Reicher, S. (1986) Contact, Action and Racialization: Some British Evidence. In Contact and Conflict in Inter-group Encounters, edited by M. Hewstone, and R. Brown. Oxford: Basil Blackwell.

Reicher, S. (2004) The Context of Social Psychology: Domination, Resistance and Change. Political Psychology 25 (6): 40-62.

Rosen, Yigal. (2006) Does Peace Education in the Regions of Intractable Conflict Change Core Beliefs of Youth? International Conference on Education for Peace and Democracy, November 2006, Antalya, Turkey.

Rubin, Mark, And Miles Hewstone. (2004) Social Identity, System Justification, and Social Dominance: Commentary on Reicher, Jost, et al., and Sidanius et al. Political Psychology 25 (6): 823-844.

Rubin, J. Z., D. G. Pruitt, and S. H. Kim. (1994) Social Conflict: Escalation, Stalemate, and Settlement, 2nd edition. New York: McGraw-Hill.

Saunders, H. H. (1999) A Public Peace Process. New York: St. Martin's Press.

SAunders, H. (2005) Politics Is About Relationship: A Blueprint for the Citizens' Century. New York: Palgrave Macmillan.

Shapiro, Ilana. (2005) Theories of Change, edited by Guy Burgess, and Heidi Burgess. University of Colorado, Boulder: Conflict Research Consortium. Posted: September 2003. Available at http:// www.beyondintractability.org/essay/Evaluation_Reflection/. (Accessed July 6, 2011.)

Sherif, M. (1966) In Common Predicament: Social Psychology of Inter-group Conflict and Cooperation. Boston: Houghton Mifflin.

Sherif, M., O. J. Harvey, B. Jack White, W. R. Hood, and C. W. Sherif. (1961) Inter-group Conflict and Cooperation: The Robbers Cave Experiment. Norman: University of Oklahoma Book Exchange.

Sidanius, J., F. Pratto, C. van Laar, And S. Levin. (2004) Social Dominance Theory: Its Agenda and Method. Political Psychology 25: 845-880.

Sмiтh, CB. (1994) Back and to the Future: The Inter-Group Contact Hypothesis Revisited. Sociological Inquiry 64: 438-455.

Stangor, C., L. A. Sullivan, And T. E. Ford. (1991) Affective and Cognitive Determinants of Prejudice. Social Cognition 9: 359-380.

Steele, C. M., S. Spencer, And J. Aronson. (2002) Contending with Group Image: The Psychology of Stereotype and Social Identity Threat. In Advances in Experimental Social Psychology, Vol. 37, edited by M. Zanna. San Diego, CA: Academic Press.

TAJfel, H. (1974) Social Identity and Inter-Group Behavior. Social Science Information 13: 65-93.

Tajfel, H., AND JC Turner. (1979) An Integrative Theory of Social Conflict. In The Social Psychology of Inter-group Relations, edited by WG Austin, and S. Worchel. Monterey, CA: Brook/Cole.

Tajfel, H, and JC Turner. (1986) The Social Identity Theory of Inter-Group Behavior. In Psychology of Inter-group Relations, edited by S. Worchel, and W Austin. Chicago: Nelson Hall.

Tajfel, H., M. Billig, R. Bundy, and C. Flament. (1971) Social Categorization and Inter-Group Behavior. European Journal of Social Psychology 1: 149-178.

Volkan, V. D. (1991) Official and Unofficial Diplomacy: An Overview. In The Psychodynamic of International Relationships: Unofficial Diplomacy at Work, edited by V. D. Volkan, D. Julius, and J. Montville. Lexington, MA: Lexington Books. 2.

WAgner, U., AND U. Machleit. (1986) 'Gastarbeiter' in the Federal Republic of Germany: Contact Between Germans and Migrant Populations. In Contact and conflict in inter-group encounters, edited by M. Hewstone, and R. Brown. New York: Basil Blackwell.

Weiss, C. (1998) Evaluation: Methods for Studying Programs and Policies. Upper Saddle River, NJ: Prentice Hall.

Yogev, A., N. S. Ben-Yehoshua, And Y. Alper. (1991) Determinants of Readiness for Contact with Jewish Children among Young Arab Students in Israel. Journal of Conflict Resolution 35 (3): $547-562$. 